\title{
A rare presentation of ovarian fibrothecoma: a diagnosing dilemma
}

\author{
Kalaivani Logesh*, Latha prasanna
}

Department of Obstetrics and Gynecology, Royal care Superspeciality Hospital, Coimbatore, Tamil Nadu, India

Received: 29 January 2018

Accepted: 06 March 2018

\section{*Correspondence:}

Dr. Kalaivani Logesh,

E-mail: drkalai24@yahoo.co.in.

Copyright: (c) the author(s), publisher and licensee Medip Academy. This is an open-access article distributed under the terms of the Creative Commons Attribution Non-Commercial License, which permits unrestricted non-commercial use, distribution, and reproduction in any medium, provided the original work is properly cited.

\begin{abstract}
Ovarian Fibrothecoma are uncommon tumors of gonadal stromal cell origin accounting for 3-4\% of all ovarian tumours. Ovarian fibrothecoma are composed of an admixture of fibrous and the comatous elements. The stromal cell tumors are probably the most inaccurately diagnosed tumor of the female gonad, clinically and histologically. Rarely benign tumours can present with elevated CA125. Here we discuss a rare presentation of Ovarian Fibrothecoma in a 52 years postmenopausal woman with large pelvic mass with ascites and elevated CA125 which we mistook for malignancy. Hence accurate diagnosis is more important before extensive surgical intervention.
\end{abstract}

Keywords: Ascites, CA 125, Fibrothecoma, Ovary

\section{INTRODUCTION}

Ovarian fibrothecoma is a very rare tumours of stromal call type. These tumours are of gonadal cell types which are derived from the coelomic epithelium or the mesenchymal cells of the embryonic gonads. They are mostly benign and $90 \%$ are unilateral. ${ }^{1}$ Histologically these tumors are characterized by the presence of spindle, oval or round cells admixed with presence of lipid laden theca cells.

These tumours affect all age groups and in $70 \%$ of the cases the patients are diagnosed as having stage 1 lesions at presentation contrary to epithelial ovarian tumours where patients present with stage 111 or $1 \mathrm{~V}$ disease. Surgical resection is the preferred treatment and is generally associated with a good prognosis.

Fibrothecoma can also present with elevated CA125 and ascites as in our case where we mistakenly made a diagnosis of malignant ovarian tumor ${ }^{2}$. Hence, extensive preoperative diagnosis of fibrothecoma should be made before surgical intervention.

\section{CASE REPORT}

52 yrs old postmenopausal woman presented with lower abdominal pain and abdominal distension for 2 weeks. No H/o of postmenopausal bleeding. H/o of loss of appetite was present.

On examination, a solid mass of size $10 \times 8 \mathrm{~cm}$ occupying right iliac and suprapubic region was palpable. Lower border felt, mobile from side to side.

Biochemical investigations done and found to be normal. CA 125 done $-81 \mathrm{IU} / \mathrm{ml}$. Ultrasound shows right ovarian solid mass with internal vascularity with ascites. Other ovary normal. Endometrial thickness is $3 \mathrm{~mm}$. (Figure 1)

Risk malignant index (RMI) score- 729. It is calculated by the formula

USG score x CA125 x Menopausal status. In 1995 Jacobs et all proposed RMI score for diagnosing malignant ovarian tumor. ${ }^{3}$ Score $>250$ is taken as malignant ovarian tumour. In our case it is 729 , So we suspected 
malignancy. But studies shows limited value RMI score and its uses in diagnosing tumours. ${ }^{4}$

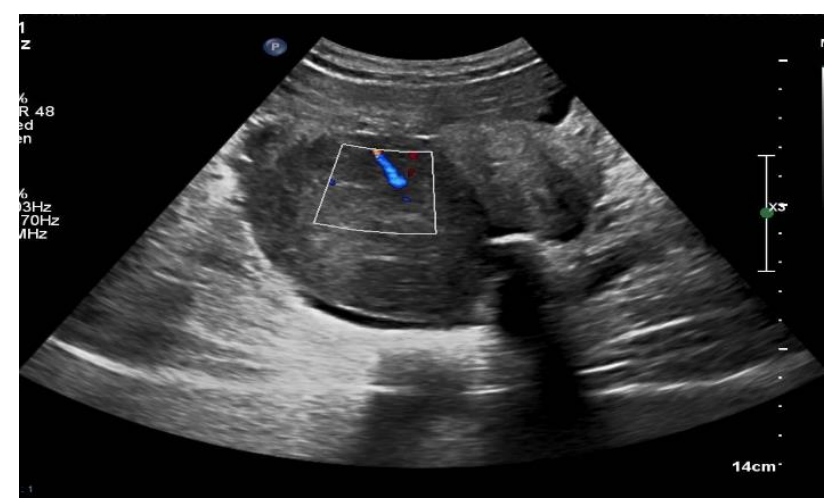

Figure 1: Ultrasonogram showing solid mass.

CECT abdomen and pelvis shows Right ovarian well defined enhancing mass lesion $8 \times 6 \times 7$ with ascites. No evidence of lymph node enlargement. Other solid organs normal.(Figure 2). MRI not done. Proceeded with Staging laparotomy. Ascitic fluid sent for cytology. Total abdominal hysterectomy and bilateral salphingo oopherectomy done (Figure 3, 4).

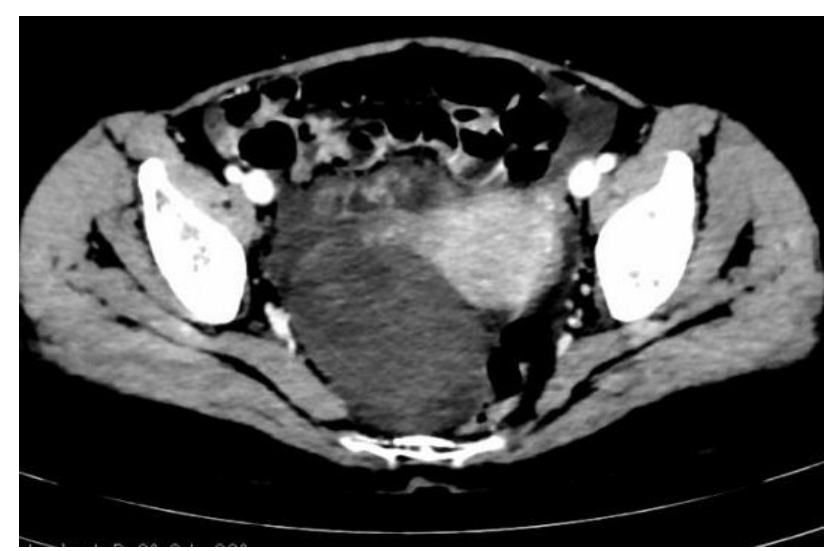

Figure 2: CECT pelvis showing solid mass with ascites.

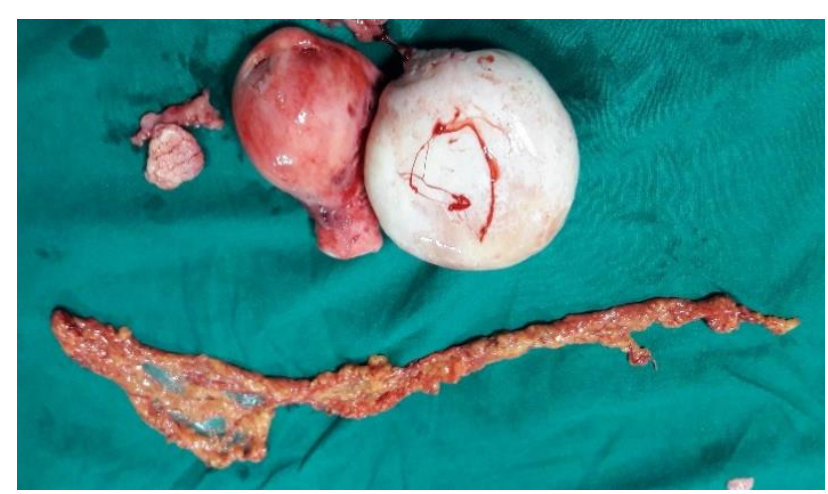

Figure 3: Specimen of total abdominal hysterectomy and bilateral salpingo-oopherectomy with omentum.
There were no peritoneal deposits. Lymph nodes and omentum sent for HPE. Postoperative period was uneventful. HPE-Tumor composed of fibrous spindle cells with indistinct borders and collagenous stroma intermixed with polygonal lipid laden cells having bland nuclei (Figure 5, 6). There is no evidence of cellular atypia or increased mitotic activity. Omentum and lymph nodes free of tumor deposits.

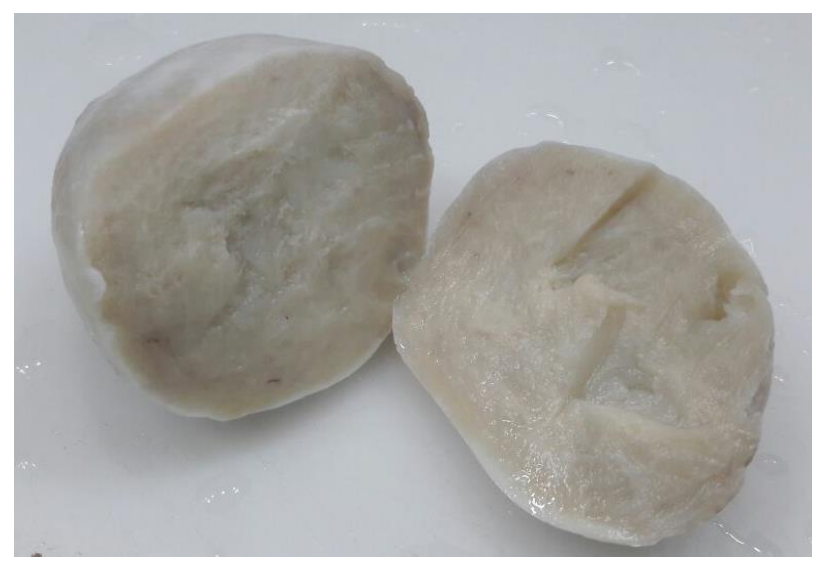

Figure 4: Cut section of tumor

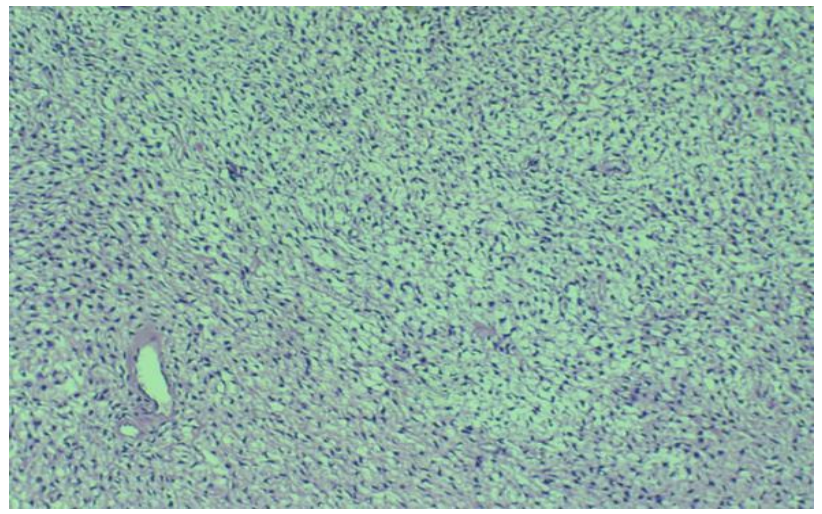

Figure 5: Histopathological features of ovarian fibrothecoma showing spindle cells and vacuolated cytoplasm

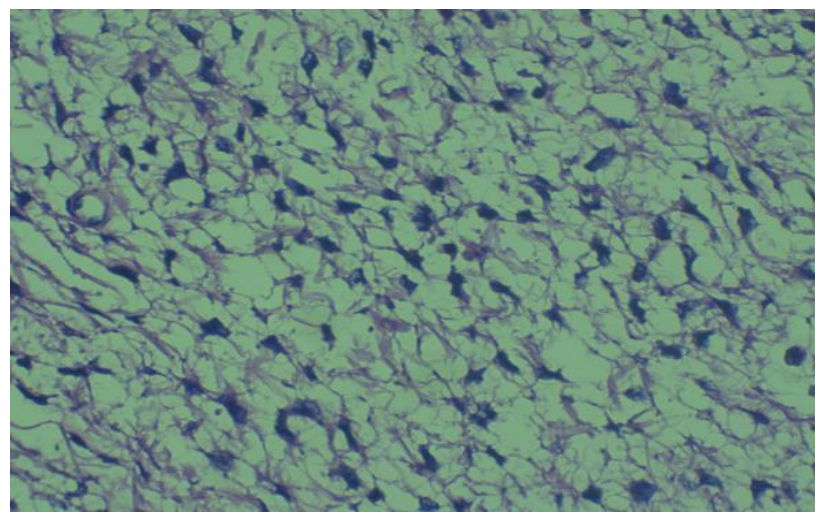

Figure 6: High power showing vacuolated cytoplasm. 


\section{DISCUSSION}

Fibrothecoma are rare tumors which are rarely malignant. The clinical presentation of ovarian fibrothecoma is relatively nonspecific namely pelvic pain, abdominal pain or abdominal distension. It occurs predominantly in postmenopausal women and are usually solid, slightly loculated. Ovarian fibromas may be associated with Meig syndrome (fibroma, ascites, hydrothorax). Our case was associated only with ascites and elevated CA $125 .^{5}$

Some fibrothecomas are hormonally active, showing estrogenic manifestations, such as irregular bleeding, endometrial hyperplasia and endometrial carcinoma. ${ }^{6}$ However, in the present case so such abnormality was observed. On gross examination the tumor has a white whorled appearance closely resembling uterine leiomyomas.

Mak et al have described the presence of characteristic computerised tomograph patterns of fibrothecoma. Ovarian fibrothecomas usually appear as a homogenous solid tumors with varying degrees of enhancement. ${ }^{7}$ In $79 \%$ cases the tumor appears as a solid mass with delayed accumulation of contrast medium, while in $20 \%$ of the cases the tumor is partly or mainly cystic thus making differential diagnosis from other ovarian masses, such as serous cystadeno fibromas or even malignant tumors difficult.

MRI is an excellent imaging modality for the detection and characterization of ovarian fibromas and fibrothecomas. ${ }^{8}$ Triano et al reported the MRI findings, where all the lesions had homogenous low signal intensity on T1 and T2 weighted images, which shows predominantly fibrous component. ${ }^{9}$ Correct diagnosis and excellent clinical skill is needed to diagnose these tumors on imaging which decreases patient anxiety and avoids unnecessary invasive procedures. This type of presentation is very rare. Hence, we have presented this case. Thus, an accurate diagnosis preoperatively may prevent extensive surgical intervention.

\section{CONCLUSION}

The stromal cell tumours are probably the most inaccurately diagnosed lesions of the female gonad. Presented this case for its rare clinical presentation. Ovarian fibrothecoma with elevated CA125 and ascites is a rare presentation. All Solid tumors with elevated CA125 and ascites need not be malignant, benign tumors are also possible. Hence preoperative diagnosis is very important to prevent extensive surgical intervention.

Funding: No funding sources

Conflict of interest: None declared

Ethical approval: Not required

\section{REFERENCES}

1. Chechia A, Attia L, Temime RB, Makhlouf $\mathrm{T}$, Koubaa A. Incidence, clinical analysis, and management of ovarian fibromas and fibrothecomas. Am J Obstet Gynecol. 2008;199(473):e1-4.

2. Loizzi V, Cormio G, Resta L, Fattizzi N, Vicino M, Selvaggi L. Pseudo-Meigs syndrome and elevated CA125 associated with struma ovarii. Gynecol. Oncol. 2005;97(1):282-4.

3. Jacobs I, Oram D, Fairbanks J, Turner J, Frost C, Grudzinskas J. A risk of malignancy index incorporating CA 125, ultrasound and menopausal status for the accurate preoperative diagnosis of ovarian cancer. BJOG: Int J Obstet Gynaecol. 1990;97(10):922-9.

4. Numanoglu C, Kuru O, Sakinci M, Akbayır O, Ulker V. Ovarian fibroma/fibrothecoma: retrospective cohort study shows limited value of risk of malignancy index score. Aust NZ J Obstet Gynaecol. 2013;53(3):287-92.

5. Samanth KK, Black WC. Benign ovarian stromal tumors associated with free peritoneal fluid. Am J Obstet Gynecol. 1970;107(4):538-45.

6. krishnan D,Kumar K,Thomas AA.Unilateral ovarian fibrothecoma with menorrhagia. Malays J Pathol. 2014;36(1):55-8

7. Mak CW, Tzeng WS, Chen CY, Computed tomography appearance of ovarian fibrothecomas with and without torsion. Acta Radiol. 2009;50(5):570-5.

8. Wu B, Peng WJ, Gu YJ, Cheng YF, Mao J. MRI diagnosis of ovarian fibrothecomas: tumour appearances and oestrogenic effect features. $\mathrm{Br} \mathrm{J}$ Radiology. 2014;87(1038):20130634.

9. Troiano RN, Lazzarini KM, Scoutt LM, Lange RC, Flynn SD, McCarthy S. Fibroma and fibrothecoma of the ovary: MR imaging findings. Radiology. 1997;204(3):795-8.

Cite this article as: Logesh K, Prasanna L. Fetal A rare presentation of ovarian fibrothecoma: a diagnosing dilemma. Int J Reprod Contracept Obstet Gynecol 2018;7:1654-6. 